\title{
The influence of determining factors on the results of the student first session at the university
}

\author{
Elena Malaya ${ }^{1, *}$, Sergey Vorobev $^{1}$, Olga Baryshnikova $^{1}$ \\ ${ }^{1}$ Don State Technical University, pl. Gagarina, 1, Rostov-on-Don, 344000, Russia
}

\begin{abstract}
The object of the research was the results of the student first examination session for the technical direction of full-time education. The aim of this work was to study the factors that influence on the results of the student first session. For this, a questionnaire for freshmen was developed, and an anonymous questionnaire was conducted immediately after the first session. The results of the questionnaire were processed, analyzed, discussed and appropriated recommendations for the educational process were developed.
\end{abstract}

\section{Introduction}

As you know, the session is the final calendar period of the academic semester. Only those students who have completed the full scope of reporting by discipline and attended classes are allowed to the session. Attending lectures is a prerequisite for the educational process. For yesterday's schoolchildren a lecture is a new type of educational activity. The main goal of a lecture or a course of lectures is to:

- to acquaint with a certain branch of science, with its latest achievements and problems;

- to reveal its methodological foundations;

- to contribute to the formation of a scientific outlook;

- to indicate the ways of applying this knowledge in the relevant fields of activity.

In order for a lecture to be complete, it must be a school of thinking, in order to form students' scientific method of cognition [1]. Even K.A. Timiryazev noted that the lecturer's task is to show, first of all, not "what" is known, but "how" is cognized. The lecture should open the doors to science for the audience and introduce them to the laboratory of scientific thinking [2]. There are several principles that determine the scientific nature of lectures:

1. The principle of objectivity and knowability of the world. This principle allows the lecturer to scientifically approach the solution of questions about the subject and the source of scientific knowledge, about the truth of its position.

2. The principle of comprehensive consideration of the object of science.

3. Development principle. This principle includes two points: the development of the object of science and the development of science itself.

4. The principle of connection between science and practice. The main purpose of science, as we know, is to serve practice.

\footnotetext{
*Corresponding author: elevicma@mail.ru
} 
5. The principle of concreteness of consideration. [3].

It is a lecture that is the first type of educational and research work that a student encounters when starting his studies at a university. On the one hand, a lecture is one of the main forms of studies in higher educational institutions, which is a systematic, consistent oral presentation by a teacher of a certain section of a particular science or academic discipline, on the other, it is a special form of independent work with educational material. A lecture does not replace a book, it only points the way to it, revealing a topic, a problem, highlighting the main, essential, what should be paid attention to, indicates the directions to be followed, achieving a deep understanding of the problem posed, and not the general picture. The university teacher does not set himself the task of teaching to listen, his main goal is to convey the essence of the problem posed, therefore, when giving a lecture, the teacher does not dwell on the plan and conclusions, does not reinforce the most important points of the lecture with intonation and does not repeat them. The lecture requires a lot of independent work from the listener. During the lecture, the main stages in the development of the lecturer's thought, conclusions and generalizations are recorded. Moreover, it is necessary to record information not only for later memorization, but also for further work with a book, textbook, reference book, collection of normative documents. The main requirements for the lecture: scientific nature, accessibility, consistency, clarity, emotionality, feedback from the audience, communication with other organizational forms of education. [4]

The purpose of practical lessons is to consolidate knowledge by involving students in solving various kinds of educational and practical problems, developing skills in using computers and reference literature. Practical exercises should cover the most important sections of the course, providing for the formation of skills. On them, students must master those calculation methods that they will have to face in their professional activities as designers, technologists, designers.

The purpose of laboratory classes is an in-depth study of the scientific and theoretical foundations of the academic discipline and mastering modern skills in conducting an experiment in this subject area. In laboratory work, students are involved in the process of cognition of physical, chemical, electrical and other phenomena, taking direct part in experiments. This allows you to study the operation of machines, devices, master the techniques of researching processes and analysis of substances, skills in working with laboratory equipment. Thus, the laboratory practice not only develops certain experimental skills in students, but also develops scientific thinking, awakens interest in science, introduces them to scientific research, forms the ability to penetrate into the essence of the phenomena and processes being studied. Consultation of the lecturer before the exam can be used to achieve the following goals: systematization of the passed material; parsing the most difficult issues; analysis of the most common errors; answers to students' questions about the course; solving problems of the examination type; information of the teacher about the methodology of the exam; solving organizational issues related to the attendance of students for the exam, their behavior on the exam, etc.

Nowadays, when the importance of independent individual work of students increases significantly, the role of consultations is becoming more and more important. In the world practice of higher technical education, consultations have a greater specific weight than in the domestic one, and is provided by a special institute of mentors and tutors.

Independent work of students (IWS) is a planned cognitive, organizational and methodological activity, carried out without the direct help of a teacher, in order to achieve a specific result. An integral part of the CDS is individual lessons with students. The effect of the CDS can be obtained only when it is organized and implemented in the educational process as an integral system that permeates all stages of education at a university. The overwhelming majority of students who entered universities are little known about the forms and methods of organizing educational and cognitive activities, including independent work. 
As a result of the research, it was determined that when determining the quality of the results of the first session, attention is mainly paid to the process of teaching and preparing the first-year students themselves. However, practically no attention is paid to the teachers themselves, their teaching methods, their adaptation support of freshmen in the form of explanatory conversations, examples of senior students. It is when communicating with senior students that freshmen try to gain information about the methodology for taking the exam of one or another teacher and build their own model of behavior on the exam. Meanwhile, it is the period of the examination session that becomes the stage in life when the student has to make a choice: either to remain guided in the process of studying at the university, or to begin to become a subject of activity. And from this point of view, it is very significant to study those forms of adaptation that the freshman considers acceptable for himself.

In domestic and foreign psychology, L.S. Vygotsky [5] and O. Gavrilova [6] distinguish two forms of adaptation: static and dynamic. The first arises when a person is oriented towards smoothing out the discrepancy between his own characteristics and the conditions of life. The static form of adaptation manifests itself in different ways and is associated with a change in only some of a person's habits, while his personality and character remain unchanged. This form of adaptation allows you to resolve the contradictions between the individual and the group, the individual and socially developed ways of performing activities. In this case, the goal of a person becomes the search for a niche, a place in the existing structure of activity or labor and interpersonal relations to smooth out these contradictions. So, for example, a slow person, realizing static forms of adaptation, finds convenient ways of performing activities that require some delay in the reaction, avoids activities that require impromptu. At the same time, he does not cease to be slow. The activities of those who perform work together with him do not fundamentally change.

As noted by many modern researchers Shcherbatykh, Yu.V. [7], Avdienko G.Yu. [8], Andreeva D. A. [9], Dubovitskaya T. D. [10], Rean A. A., [11], Smantser A. P. [12], KitaevSmyk L. A. [13], Godunova L.N. [14], the most difficult process of adaptation occurs in connection with the new conditions of the learning process at the university, which differ from the school (the so-called didactic adaptation). The examination session is one of those new conditions of educational and professional activity of freshmen, which complicate the process of adaptation of students as a whole.

The first session bears a great emotional, intellectual and psychophysiological load, since the student has not yet developed the habits of passing such a test in this particular educational institution, in this subject. In addition, the focus on the assessment of competencies in accordance with the Federal State Educational Standard of Higher Professional Education has changed both the procedure for examinations in the traditional sense and the methods of preparation for them, ways of adapting to the stressful conditions of life during this period. In addition to understanding the theories learned, the examiner must demonstrate the ability to take advantage of their main points. This is especially evident in the study of technical disciplines, as indicated in the works of O.P. Cherednichenko $[15,16]$. The embodiment of the accession of students' human capital by means of higher education is considered in the works of A.L. Blokhin [17.18].

\section{Materials and methods}

Freshmen students are recent schoolchildren who have had experience with teachers for 11 years. Upon entering the university, they retain the habit of treating teachers as teachers. Students do not yet have a particular idea of academic degrees and scientific titles, scientific achievements and scientific schools of their mentors. Of course, students have to adapt to the new learning style, taking into account the requirements of teachers and the requirements of 
the university itself. Therefore, having come to a university, a former student who has successfully passed the USE is not psychologically ready to become a professional, understand the principles of the theories being studied and connect them with the tasks of professional activity, look for new solutions, and become a subject of educational and professional activities.

For students, a rating control system and a session twice a year become an innovation. Undoubtedly, this is a physical and psychological stress. That is why experienced teachers take this factor into account and during the period of training students in the first semester they carry out a kind of adaptation measures, from the first day they introduce them to the new form of training and the rules for preparing for the session.

When considering the results of the session, the preparation of the students themselves was almost always considered first of all. But the influence of the teachers themselves on the quality of student preparation practically did not occur. The authors have developed a questionnaire for first-year students of the technical direction of DSTU training. Before the questionnaire survey, the author conducted a conversation with students. He offered to analyze the reasons for the results obtained. If the result is very good, then it is luck or the student's merit. If the result is not very good, and sometimes even low, then who is the student himself to blame. After a preliminary interview, it was proposed to take a survey. The survey was conducted anonymously. The questionnaire included the characteristics of the activities of all teachers who were examiners in the first session, the activities of each teacher had to be assessed from 0 to 10 points:

- presented the material clearly, clearly, accessible;

- monitored student attendance;

- prepared in advance for the exam, test;

- during the exam (test) was objective to me;

- during the exam (test) was objective towards other students;

- interested in the absence of debts in this discipline;

- gives much more importance to their discipline than to others;

- is it friendly towards students;

- pleasant to talk to;

- inspires confidence in you;

- tactful in dealing with students;

- observes the subordination;

- emotionally restrained.

Among the questions were presented such that reflected on the quality of preparation for the exam of the student himself:

- I attended classes in this discipline- I kept a synopsis for this discipline;

- I submitted all reports on this discipline on time;

- I have conscientiously prepared for the exam (test) in this discipline;

- I felt (a) fear when passing the exam (credit) to this teacher;

- I need additional advice on this discipline.

The survey was carried out in three groups with an average number of 27 people. The results of the survey are presented in Figures 1-3. 


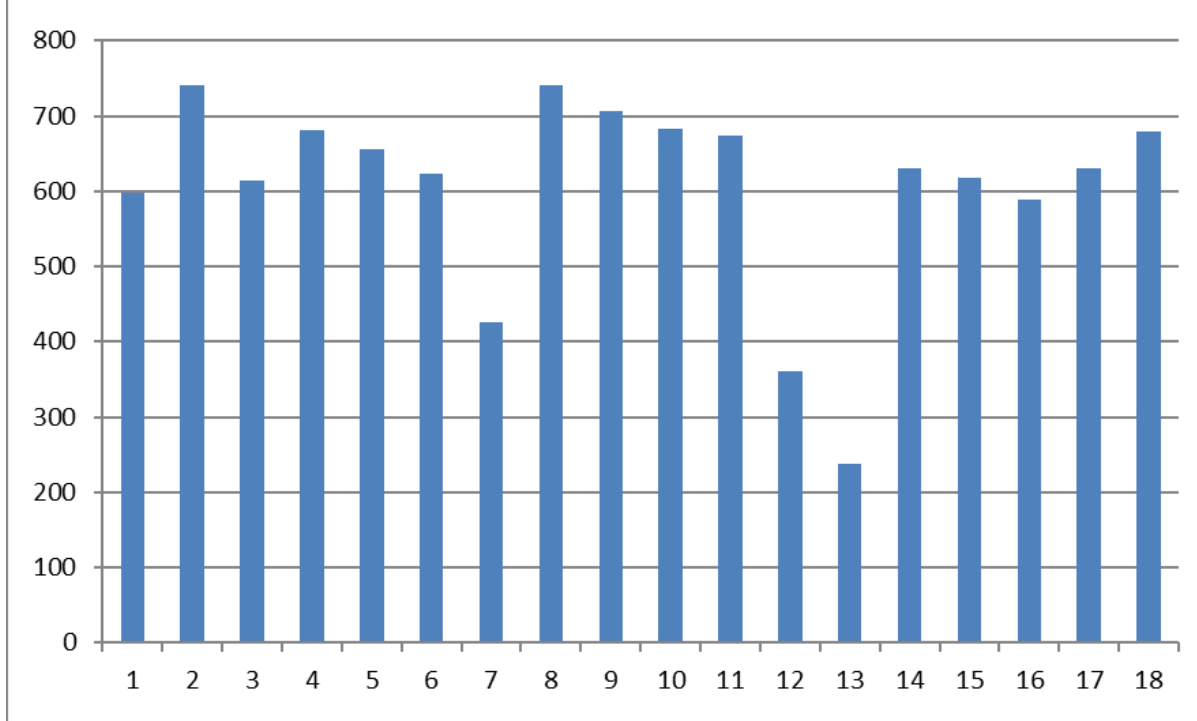

Fig. 1. Results of the survey of group A.

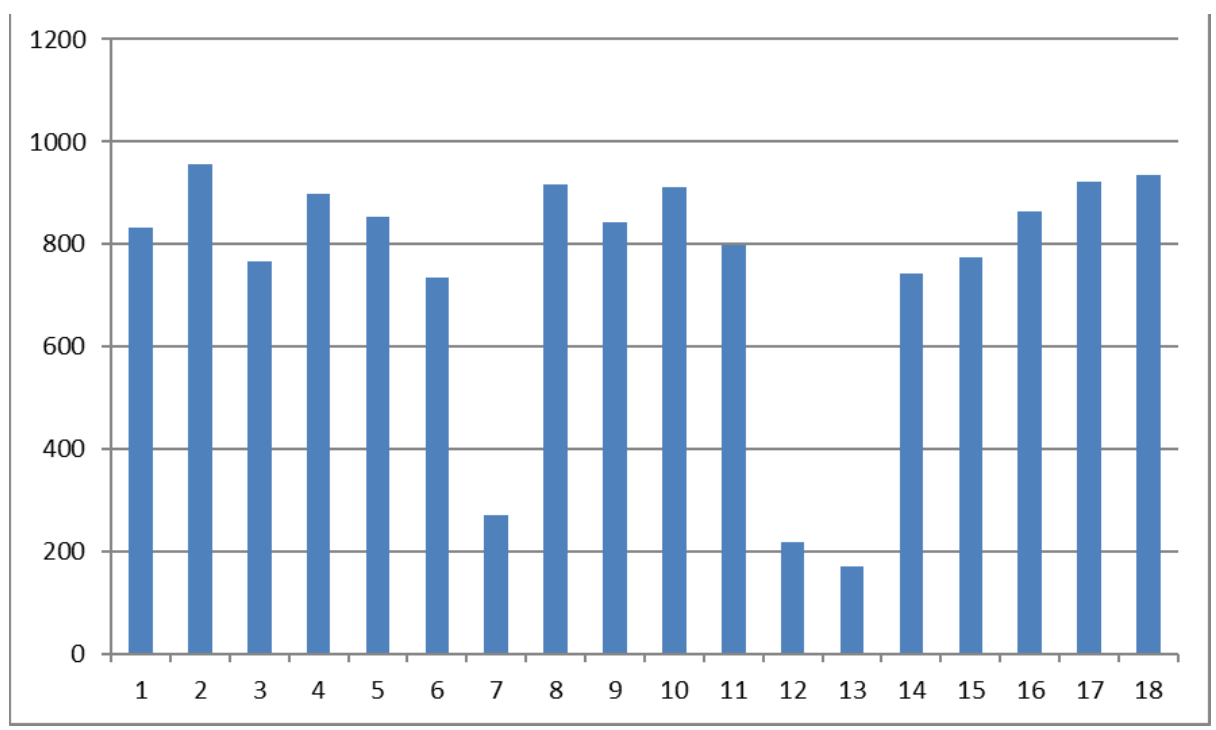

Fig. 2. Results of the survey of group B. 


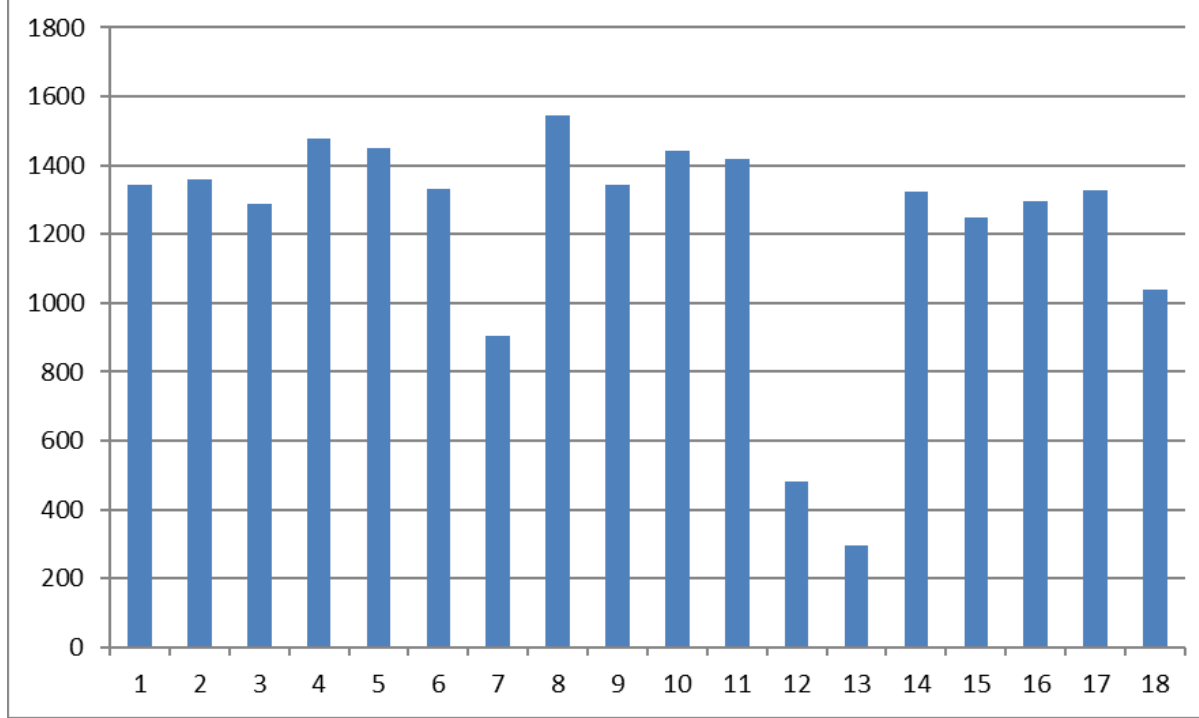

Fig. 3. Results of the survey of group C.

\section{Results}

As a result of the survey, it was determined that almost all teachers monitored student attendance, and students, in turn, attended classes in this discipline and took notes. Approximately half of teachers attach much more importance to their particular discipline compared to the rest of the studied. With the high demands of attending classes, not all teachers prepared students for the upcoming exams in advance. Interesting results were obtained on the objectivity of the teacher during the exam - the teacher was more objective towards me in comparison with the objectivity towards my classmates. The negative aspects should be attributed to the fact that not all teachers present the material clearly and easily and the low interest of teachers in the absence of student debts. Almost all students answered that they had submitted reports on the studied disciplines in a timely manner and noted that they had conscientiously prepared for the exam (test). Despite the anxiety experienced before passing the first session, only one quarter of the students admitted that they were afraid of passing the exams. And approximately the same number of students determined that they needed additional advice on this subject from this teacher. The need was associated either with the delivery of debt, or with an explanation of certain provisions of theory or practice.

When considering the section on pedagogical tact, the following results should be noted. Almost all students noted that teachers are friendly towards students and pleasant to talk to. Many of the teachers inspire confidence and with many students are ready to share their problems and get advice. The students also noted the tactfulness of the teachers. But with a few exceptions. Unfortunately, sometimes some teachers engage in inappropriate behavior towards students and cause psychological trauma in the form of labeling of learning disabilities. It was pleasant to note that practically all teachers observe the chain of command. But unfortunately, according to the grades of students, not all teachers are emotionally restrained. 


\section{Discussion}

After processing the questionnaire, the results were discussed both among students and among teachers. The students were interested in the information received that the role of teachers in preparing students for the examination session is very important, that teachers, according to students, are not all interested in the absence of students' debts (they even tried to trace the selfish component). The students were surprised to note that the teachers were more objective towards them than towards other students during the exam, and only a quarter of the students were afraid of passing the exam. Since the names of the teachers were included by the students in the columns of the questionnaire, the information received for the teachers that they were not equally objective with the students during the exam was very important, as well as the lack of interest in the absence of debts among students. Some instructors stated that they opposed the question of the instructor's emotional restraint, referring to the discipline in the group. Although, according to the authors, the teacher should behave diplomatically and with restraint in any difficult situation, trying to smooth out the unfriendly atmosphere in the classroom both during classes and during the exam, when the emotional intensity increases. Unfortunately, some teachers treated the information formally, referring to the bias of students due to their increased demands on students in the subject taught.

\section{Conclusions}

Based on the questionnaire survey and processing of the results, it can be concluded that the quality of the results of the first session of students is influenced by many factors. In addition to such important ones as strict attendance of classes, timely execution and submission of reports, independent preparation for the exam, physical health and mental balance are still important and moments beyond the student's control are the support of the teacher himself in preparation for the session from the first day of study at the university. The success of the first session of students largely depends on the qualifications of the teacher, his pedagogical experience and skill. It is not for nothing that in the student environment, not those who entered the university, but who successfully passed the first session, can rightfully call themselves students. Based on the results of the questioning, the faculty teachers made conclusions for themselves and outlined corrective measures in the educational process with the aim of adaptive support for freshmen students and successful passing of the session. All teachers noted that the survey data are useful for further pedagogical activity.

\section{References}

1. E.V. Malaya, A.V. Pavlova, Priorities of pedagogy and modern education Penza 5, 181183 (2018)

2. E.V. Malaya, A.V. Pavlova, Don's young explorer 1(16), 103-107 (2019)

3. L.N. Godunova, E.V. Malaya, Innovation processes in science, economics and education: theory, methodology, practice. monograph (Penza, 2017)

4. E.V. Malaya, Modern problems of multilevel education, 345-349 (2015)

5. L.S. Vygotsky, Pedagogical psychology (Pedagogika-Press, Moscow, 1992)

6. O.V. Gavrilova, Humanitarian research 1(41), 183-189 (2012)

7. Yu.V. Shcherbatykh, Higher education in Russia 3, 111-115 (2000)

8. G.Yu. Avdienko, Bulletin of psychotherapy 24, 8-14 (2007)

9. D.A. Andreeva, Man and society XI-II, 25-27 (1973) 
10. T.D. Dubovitskaya, A.Ya. Krylova, Psychological science and education 2, 3-9 (2010)

11. A.A. Rean, A.R. Kudashev, A.A. Baranov, Psychology of personality adaptation: Textbook (Med. press, SPb., 2002)

12. A.P. Smantser, Theory and practice of the implementation of continuity in teaching schoolchildren and students (BSU, Minsk, 2011)

13. L.A. Kitaev-Smyk, Psychology of stress (Academic Project, M., 2009)

14. L.N. Godunova, V.T. Babkin, E.G. Sidelnikova, Socio-economic and technicaltechnological problems of development of the service sector: collection of articles (RAS YURGUES, Rostov-n / D, 2009)

15. A.V. Kurbesov, O.P. Cherednichenko, Educational Informatics 2, 20-25 (2017)

16. O.P. Cherednichenko, L.A. Filonenko, Problems of graphic training of students of technical universities in the context of a modern competence-based approach

17. A.L. Blokhin, Collection of scientific papers based on the materials of the XXIX International Scientific and Practical Conference. Under the general editorship of A.V. Tugolukova, 40-42 (2018)

18. A.L. Blokhin, Scientific notes of the University P.F. Lesgaft 2(156), 25-28 (2018) 